Document downloaded from:

http://hdl.handle.net/10251/180859

This paper must be cited as:

Correia, D.; Costa, C.; Sabater I Serra, R.; Gómez-Tejedor, J.; Teruel Biosca, L.; De Zea Bermudez, V.; Esperança, J.... (2019). Molecular relaxation and ionic conductivity of ionic liquids confined in a poly(vinylidene fluoride) polymer matrix: Influence of anion and cation type. Polymer. 171:58-69. https://doi.org/10.1016/j.polymer.2019.03.032

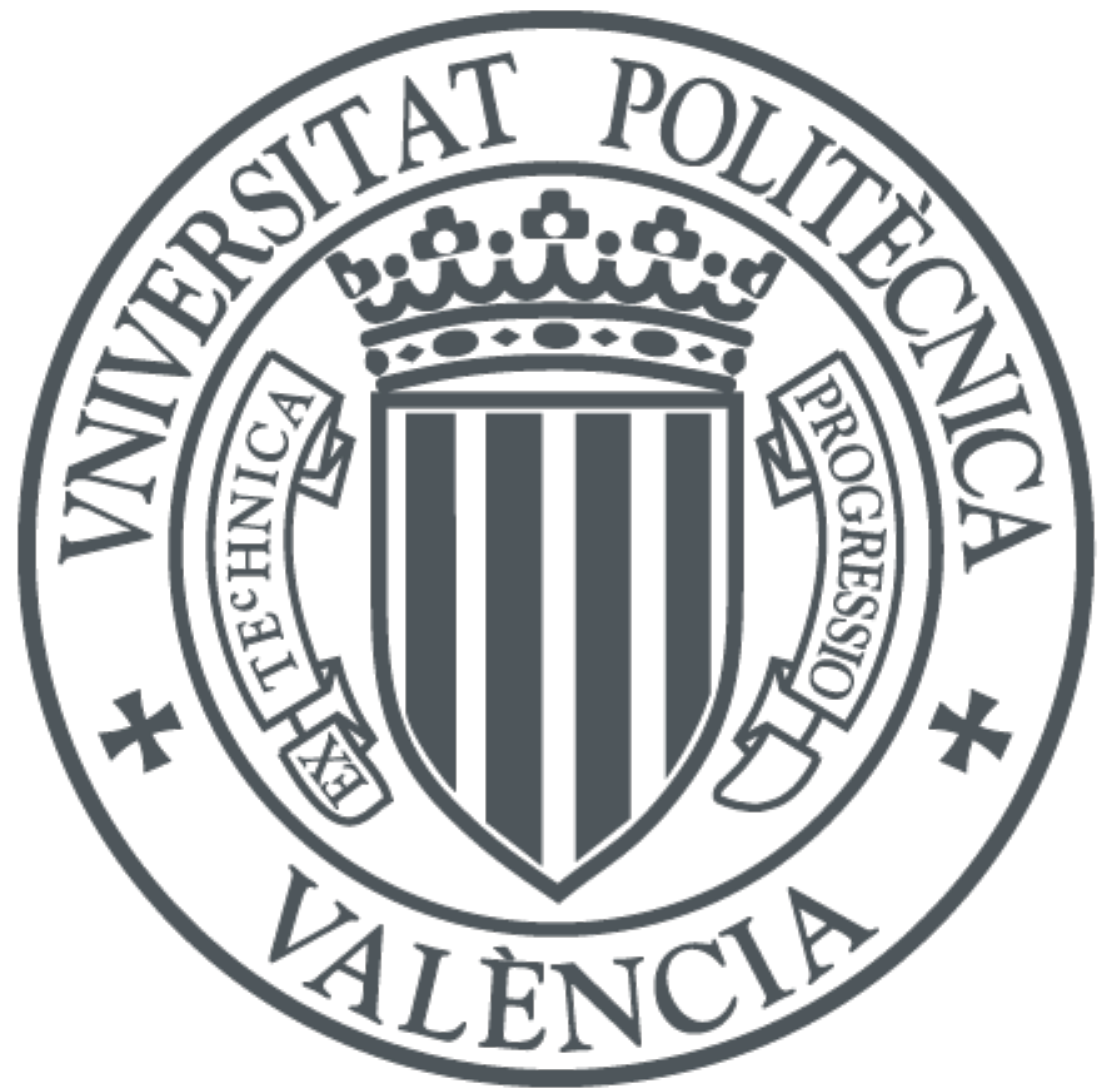

The final publication is available at

https://doi.org/10.1016/j.polymer.2019.03.032

Copyright Elsevier

Additional Information 


\section{Molecular relaxation and ionic conductivity of ionic liquids confined in \\ a poly(vinylidene fluoride) polymer matrix: influence of anion and \\ cation type}

D. M. Correia ${ }^{1,2}$, C. M. Costa ${ }^{3, *}$, R. Sabater i Serra ${ }^{4,5}$, J.A Gómez Tejedor ${ }^{4,5}$, L. Teruel Biosca $^{4}$, V. de Zea Bermudez ${ }^{1}$, J.M.S.S. Esperança ${ }^{6}$, P. M. Reis ${ }^{6}$, A. Andrio Balado ${ }^{7}$, J. M. Meseguer-Dueñas ${ }^{4,5}$, S. Lanceros-Méndez ${ }^{2,8}$, J. L. Gomez Ribelles ${ }^{4,5}$

${ }^{1}$ Department of Chemistry and CQ-VR, University of Trás-os-Montes e Alto Douro, 5000-801Vila Real, Portugal

${ }^{2}$ BCMaterials, Basque Center for Materials, Applications and Nanostructures, UPV/EHU Science Park, 48940 Leioa, Spain

${ }^{3}$ Centro de Física, Universidade do Minho, 4710-057 Braga, Portugal

${ }^{4}$ Centre for Biomaterials and Tissue Engineering, CBIT, Universitat Politècnica de València, 46022 Valencia, Spain

${ }^{5}$ Biomedical Research Networking Center on Bioengineering, Biomaterials and Nanomedicine (CIBER-BBN), Valencia, Spain

${ }^{6}$ LAQV, REQUIMTE, Departamento de Química, Faculdade de Ciências e Tecnologia Universidade Nova de Lisboa, 2829-516 Caparica, Portugal

${ }^{7}$ Departament de Física, Universitat Jaume I, 12071 Castelló, Spain

${ }^{8}$ IKERBASQUE, Basque Foundation for Science, 48013, Bilbao, Spain

Keywords: PVDF; ionic liquid, dielectric response; conductivity; electric modulus

\footnotetext{
* Corresponding Authors

C.M. Costa (cmscosta@ fisica.uminho.pt),
} 
Abstract: Blends of poly(vinylidene fluoride) (PVDF) and ionic liquids (ILs) with different cations and anions have been prepared by solvent casting. The IL content was the same in all blends of the series. Molecular relaxation and ionic conductivity have been systematically studied by broadband dielectric relaxation spectroscopy (BDS) in wide frequency $(0.1 \mathrm{~Hz}$ to $1 \mathrm{MHz})$ and temperature ranges $\left(-120\right.$ to $\left.150{ }^{\circ} \mathrm{C}\right)$ and the results have been analyzed in terms of dielectric modulus $M^{*}(\omega)$ and conductivity $\sigma^{*}(\omega)$ formalisms. The main relaxation process ( $\beta$-relaxation) of the amorphous phase of the blend that integrates amorphous polymer chain segments and IL molecules was observed. Significant differences in the Vogel-Fulcher-Tammann (VFT) fitting parameters in the PVDF/IL blends with different anions were detected. The conductivity $\sigma^{*}(\omega)$ formalism shows that it is strongly dependent on the miscibility of the IL with the amorphous PVDF chains and the type of anion. The Barton-Namikawa-Nakajima $(\mathrm{BNN})$ relation $\sigma_{0} \sim \omega_{\mathrm{c}}$ is fulfilled for all PVDF/IL blends except for that containing 1-ethyl-3- methylimidazolium hydrogen sulfate, $\left[\right.$ Emim] $\left[\mathrm{HSO}_{4}\right]$. The activation energy of the $a c$ conductivity, calculated according to the Dyre model, decreases for all PVDF/IL blends with respect to neat PVDF. The structure of the cation of the IL has been found to exert less influence on the dielectric and conductivity properties of the blends. 


\section{Introduction}

Ionic liquids (ILs), defined as salts composed entirely by cations and anions, have been attracted an increasing attention due to their interesting physical-chemical properties including their green nature (replacing the common volatile organic solvents), good chemical stability, wide electrochemical stability window, non-flammability, negligible vapor pressure and high ionic conductivity [1].

Given the unique properties as solid electrolytes, polymer/ILs blends have been fabricated finding applicability in several areas, being increasingly used for sensors [2], actuators [3] and energy storage systems [4]. Sensors and actuators based on those materials have been developed, e.g. to detect organic vapors [5] and to operate at low voltages leading to large deformations $[6,7]$. The bending actuation deformation can be improved by tailoring the number and size of the cations and anions of the IL [7].

As a key area of modern technology, the development of more efficient and environmentally friendlier energy storage devices for portable electronic devices and electric vehicles is a growing need in a society increasingly dependent on both mobility and energy [8]. The most used energy storage systems are lithium ion batteries, but additional developments are needed to enhance the properties and characteristics of their different components. In this context, the polymer electrolyte (PE), placed between the two electrodes, stands out as a key element for improving battery performance and safety $[9-11]$.

Different types of PEs (solid, plasticized, gels and composites) composed of a host polymeric matrix and ionic salts and have been developed in order to obtain high ionic conductivity (ideally $10^{-2}-10^{-3}{\mathrm{~S} . \mathrm{cm}^{-1}}$ at room temperature) $[12,13]$. PEs should show ionic conductivities $<10^{-4} \mathrm{~S} . \mathrm{cm}^{-1}$ at room temperature. In addition, they should exhibit suitable mechanical and thermal properties, high chemical and electrochemical stability and simple processing [14]. 
Macroscopic ionic conduction in PEs is determined by the semi-random motion of short polymer segments, as described by the Vogel-Tamman-Fulcher (VFT) equation [15].

In recent years, the use of ILs instead of ionic salts in PEs has been extensively studied on account of their good chemical and electrochemical stability, non-flammability, negligible vapor pressure and high ionic conductivity, since the organic solvent in which the ionic salts are dissolved can cause ignition $[1,16]$.

ILs are typically formed by a quaternary ammonium cation (e.g., aliphatic quaternary ammonium), imidazolium, pyrrolidinium and piperidinium), and an inorganic/organic anion $\left(\mathrm{PF}_{6}{ }^{-}, \mathrm{OSO}_{2} \mathrm{CF}_{3}{ }^{-}, \mathrm{BF}_{4}^{-}, \mathrm{FSI}^{-}, \mathrm{TFSI}^{-}\right.$and perfluoroalkyl sulfonylimide) [17].

Different polymers have been used in PEs, such as poly(ethylene oxide) (PEO) [18], poly (acrylonitrile) (PAN) [19], poly(methyl methacrylate) (PMMA) [20] and poly(vinylidene fluoride) (PVDF), the latter showing interesting properties and characteristics for this application, due to its high dipolar moment, high dielectric constant, excellent mechanical and thermal properties, and chemically inertness, among others [21, 22].

Different PVDF/IL blends have been reported in the literature, such as PVDF/1-ethyl-3methylimidazolium bis(trifluoromethylsulfonyl)imide ([C $\left.\left.\mathrm{C}_{2} \mathrm{mim}\right]\left[\mathrm{NTf}_{2}\right]\right)[6], \mathrm{PVDF} / 1$ hexyl-3-methylimidazolium chloride $\left(\left[\mathrm{C}_{2} \mathrm{mim}_{[}\right]\left[\mathrm{NTf}_{2}\right]\right)$ [7] and PVDF/1-butyl-3methylimidazolium tetrachloroferrate $\left(\left[\mathrm{C}_{4} \mathrm{mim}\right]\left[\mathrm{FeCl}_{4}\right]\right)$ [2]. Further, these blends have been reinforced with additional fillers, such as multi-walled carbon nanotubes (MWCNTs) [23], graphene [24], silicon dioxide $\left(\mathrm{SiO}_{2}\right)$ [25], clays [26], and crystalline nanostructures [27]. Thus, the improvement of their mechanical and electrical properties has been shown [28-30], tailoring them for different applications, such as sensors and actuators and for carbon dioxide $\left(\mathrm{CO}_{2}\right)$ removing from hydrogen or gas [3, 31].

When the ILs are mixed with PVDF in a solution in a common solvent and then the solvent is evaporated, the IL can mix with the amorphous phase of PVDF [27, 32]. 
Depending on the IL type, it is possible to obtain different crystalline phases of the PVDF polymer [27, 33]. In this way, it was demonstrated that 1-butyl-3-methylimidazolium hexafluorophosphate $\left([\mathrm{Bmim}]\left[\mathrm{PF}_{6}\right]\right)$ interaction with the C-F groups of PVDF leads to crystallization of the PVDF in the $\gamma$-phase [27]. On the other hand, the incorporation of ILs, such as 1-hexyl-3-methylimidazolium chloride ([Hmim][Cl]) and 1-hexyl-3methylimidazolium bis(trifluoromethylsulfonyl)imide ([Hmim][TFSI]) promotes the electrostatic interactions between the negative charge of the IL anion with the positive side of the PVDF dipolar moments leading to the PVDF crystallization in the all-trans chain conformation characteristic of the electroactive $\beta$-phase [7].

ILs are glass-formers with a low glass transition temperature, $\mathrm{T}_{\mathrm{g}}$ [32]. Their ionic conductivity has been studied in detail by the combination of deep resistivity sounding (DRS), nuclear magnetic resonance (NMR), viscosity measurements and calorimetry techniques. The results allow concluding that the dynamics of the movement of electric charge carriers are dominated by the charge diffusion and therefore directly related to the conformational mobility and glass transition of the glass forming substance and its viscoelastic behavior [34-37].

Typically, the ionic conductivity process of IL has three regimes that are related to different processes: electrode polarization at low frequency and high temperature, ionic conduction processes at higher frequencies, and the region dominated by the ac conductivity $[34,35]$.

Due to the relevance of PVDF/IL blends in battery applications [22], as well as in other areas, such as in the development of sensors [2] or bending actuators [6], where the charge dynamics is an essential issue, the goal of the present work was to understand the molecular dynamics of PVDF/IL blends with different cations and anions, and evaluate the ionic mobility by broadband dielectric spectroscopy (BDS). PVDF/IL blend films 
were prepared by solvent casting with $25 \mathrm{wt} \%$ of IL content since this amount has been proven to be suitable to evaluate the relevant contributions to the conductivity behavior [32].

In addition, the dynamic relaxation of ILs was evaluated within the PVDF/IL blends, since the mixing of the IL with the PVDF chains in the amorphous phase may alter the mobility dynamics of the charge carriers due to the glass transition temperature $\left(\mathrm{T}_{\mathrm{g}}\right)$ of PVDF, which is around $-40{ }^{\circ} \mathrm{C}[38]$ and the $T_{g s}$ of the IL, which are well below the $\mathrm{T}_{\mathrm{g}}$ of the PVDF, around $-100^{\circ} \mathrm{C}$.

Moreover, in this work the role of different IL cations and anions on the ionic conductivity behavior was evaluated, since the dynamics of the charge carriers is linked to the conformational movements of the IL and the polymer chains. 


\section{Experimental}

\subsection{Materials}

PVDF (Solef 6020, MW = 700 kDa), N,N-dimethylformamide (DMF, $99.5 \%$ ) were acquired from Solvay and Merck, respectively. The ionic liquids, 1-ethyl-3methylimidazolium chloride $[$ Emim $][\mathrm{Cl}]$ (>98\%), 1-ethyl-3-methylimidazolium hexafluorophosphate $\quad[$ Emim $]\left[\mathrm{PF}_{6}\right] \quad(>99 \%), \quad$ 1-ethyl-3-methylimidazolium bis(trifluoromethylsulfonyl)imide, $\quad$ [Emim][TFSI $] \quad(>99 \%), \quad$ 1-ethyl-3methylimidazolium hydrogen sulfate $[$ Emim $]\left[\mathrm{HSO}_{4}\right] \quad(>98 \%)$, 1-ethyl-3methylimidazolium ethylsulfate [Emim] $\left[\mathrm{C}_{2} \mathrm{SO}_{4}\right]$ (>99\%), 1-hexyl-3-methylimidazolium bis(trifluormethylsulfonyl)imide [Hmim][TFSI] (>99\%), 1-octyl-3-methylimidazolium bis(trifluoromethanesulfonyl)imide $\quad$ [Dmim][TFSI] $\quad(>99 \%), \quad$ 1-butyl-1methylpyrrolidinium bis(trifluoromethanesulfonyl)imide [BmPyrr][TFSI] (>99\%), N,N,N-trimethyl-N-(2-hydroxyethyl) ammonium bis(trifluoromethylsulfonyl)imide $\left[\mathrm{N}_{1112 \mathrm{OH}}\right][\mathrm{TFSI}] \quad(>99 \%) \quad$ and $\quad$ trihexyl(tetradecyl)phosphonium bis(trifluoromethylsulfonyl)imide [P66614][TFSI] (>98\%) were purchased from Iolitec. Each IL was dried under vacuum at least for $48 \mathrm{~h}$ at $c a .50-60{ }^{\circ} \mathrm{C}$ before the experiments.

\subsection{Preparation of the films}

The PVDF/IL blends were prepared based on the protocol published in [39]. PVDF was dissolved in N,N-dimethylformamide (DMF) in a proportion of $15 / 85$ by weight (wt.\%) under magnetic agitation at room temperature. After complete polymer dissolution, the selected IL was added. For the study of the effect of the anion, 25\% wt. of [Emim][Cl], $[$ Emim $]\left[\mathrm{PF}_{6}\right],[\mathrm{Emim}][\mathrm{TFSI}],[\mathrm{Emim}]\left[\mathrm{HSO}_{4}\right]$, or $[\mathrm{Emim}]\left[\mathrm{C}_{2} \mathrm{SO}_{4}\right]$ were used. This cation was selected because ILs containing $\mathrm{Emim}^{+}$ions show low viscosity and high conductivity compared to other possible choices [40]. 
The same procedure was performed in order to study the effect of the cation, using the following ILs: [Emim][TFSI], [Hmim][TFSI], [Dmim][TFSI], [BmPyrr][TFSI], [N $\left.\mathrm{N}_{112 \mathrm{OH}}\right][\mathrm{TFSI}]$ or [P66614][TFSI]. The TFSI ${ }^{-}$ion was chosen on account of its low viscosity, high chemical stability and inhibition of electrolytic corrosion [41]. Table 1 summarizes the main properties of the selected ILs.

PVDF/IL blends films with $\approx 50 \mu \mathrm{m}$ of thickness were obtained after spreading the solution at room temperature on a glass substrate followed by solvent evaporation at 210 ${ }^{\circ} \mathrm{C}$ in an air oven [39]. The PVDF/IL blends will be henceforth identified by the nomenclature of the IL.

Table 1 - Main properties of the selected ILs used to evaluate the influence of anion and cation type in PVDF/IL composites.

\begin{tabular}{|c|c|c|c|c|}
\hline & IL & $\begin{array}{c}\text { Molecular weight } \\
\text { / g. mol }\end{array}$ & $\begin{array}{c}\text { Viscosity } \\
\text { / cP at } 25^{\circ} \mathrm{C}\end{array}$ & $\begin{array}{c}\text { Conductivity } \\
\text { / mS.cm-1 }\end{array}$ \\
\hline \multirow{5}{*}{ Anion effect } & [Emim][TFSI] & 391.31 & 37 & 6.63 \\
\hline & {$[\mathrm{Emim}][\mathrm{Cl}]$} & 146.62 & 62 at $80^{\circ} \mathrm{C}$ & 2.56 at $\sim 40{ }^{\circ} \mathrm{C}$ \\
\hline & {$[\mathrm{Emim}]\left[\mathrm{HSO}_{4}\right]$} & 208.24 & 1650 & ---- \\
\hline & {$[\mathrm{Emim}]\left[\mathrm{C}_{2} \mathrm{SO}_{4}\right]$} & 236.29 & 100.4 & 2.91 \\
\hline & {$[\mathrm{Emim}]\left[\mathrm{PF}_{6}\right]$} & 256.13 & 23.4 at $70^{\circ} \mathrm{C}$ & 17.12 at $\sim 60^{\circ} \mathrm{C}$ \\
\hline \multirow{6}{*}{ Cation effect } & {$[$ Emim] $[$ TFSI] } & 391.31 & 37 & 6.63 \\
\hline & [Hmim][TFSI] & 447.42 & 63.2 & 2.27 \\
\hline & [Dmim][TFSI] & 503.53 & 113 & 0.76 \\
\hline & [BmPyrr][TFSI] & 422.41 & 94.4 & 2.12 \\
\hline & {$\left[\mathrm{N}_{1112 \mathrm{OH}}\right][\mathrm{TFSI}]$} & 368.32 & 49.5 & 3.98 \\
\hline & [P66614][TFSI] & 764.01 & 337 & ----- \\
\hline
\end{tabular}




\subsection{Characterization techniques}

Dielectric measurements were carried out with an impedance analyzer Alpha-S. The isothermal experiments were performed from -120 to $150{ }^{\circ} \mathrm{C}$ (thermal stability: $0.5^{\circ} \mathrm{C}$ ) in $5{ }^{\circ} \mathrm{C}$ steps in a frequency range from $0.1 \mathrm{~Hz}$ to $1 \mathrm{MHz}$. The temperature control was assured by a Quatro Cryosystem from Novocontrol GmbH. The sample cell with active head dielectric converter was mounted on a cryostat (BDS 1100) and exposed to a heated gas stream evaporated from a liquid $\mathrm{N}_{2}$ Deward.

Circular gold electrodes (10 mm diameter) were deposited by sputtering with a Polaron Coater SC502 under an argon atmosphere onto both sides of each PVDF/IL blend to form a parallel plate capacitor.

The capacitance $(\mathrm{C})$ and the loss factor $(\tan \delta)$ were determined as a function of frequency and temperature.

The dielectric relaxation spectrum of the PVDF/IL blends is represented in terms of the complex permittivity, $\epsilon^{*}=\varepsilon^{\prime}-i \epsilon^{\prime \prime}$ :

$$
\varepsilon^{\prime}=\frac{C . d}{\varepsilon_{0} \cdot A}
$$

and

$$
\varepsilon^{\prime \prime}=\tan \delta \cdot \varepsilon^{\prime}
$$

Where $C$ is the capacitance $(\mathrm{F}), \varepsilon_{o}$ is the permittivity of vacuum $\left(8.85 \times 10^{-12} \mathrm{~F} \mathrm{~m}^{-1}\right), \mathrm{A}$ is the electrode area $\left(\mathrm{m}^{2}\right)$ and $d$ is the thickness of samples $(\mathrm{m})$.

The complex electric modulus $M^{*}$ is defined as the reciprocal of the complex relative permittivity, $\varepsilon^{*}$ :

$$
M^{*}=\frac{1}{\varepsilon^{*}}=M^{\prime}(\omega)+i M^{\prime \prime}(\omega)=\frac{\varepsilon^{\prime}(\omega)}{\varepsilon^{\prime 2}(\omega)+\varepsilon^{\prime \prime 2}(\omega)}+i \frac{\varepsilon^{\prime \prime}(\omega)}{\varepsilon^{\prime 2}(\omega)+\varepsilon^{\prime 2(\omega)}}
$$

and the complex conductivity $\left(\sigma^{*}\right)$ is calculated from the dielectric function by the following equation: 


$$
\sigma^{*}=\sigma^{\prime}(\omega)+i \sigma^{\prime \prime}(\omega)=\varepsilon_{0} \omega \varepsilon^{\prime \prime}(\omega)+i \varepsilon_{0} \omega \varepsilon^{\prime}(\omega)
$$

where $\varepsilon_{0}\left(8.85 \times 10^{-12} \mathrm{Fm}^{-1}\right)$ is the permittivity of free space and $\omega=2 \pi v$ is the angular frequency. 


\section{Results}

\subsection{Dielectric and electric modulus formalism}

Broadband dielectric relaxation spectroscopy (BDS) measurements in the frequency and temperature domains are essential to evaluate the motion of charge carriers: ions or ionpairs formed between a cation and anion, and the mutual effect of polymer segments and IL ions in polymer/IL blends [42].

Figure 1 shows the isochronal curves of the real $\left(\varepsilon^{\prime}\right)$ and imaginary $\left(\varepsilon^{\prime \prime}\right)$ parts of the dielectric permittivity for neat PVDF and for the different PVDF/IL blends. Figures 1a and $1 \mathrm{~b}$ show the effect of the anion, whereas Figures $1 \mathrm{c}$ and $1 \mathrm{~d}$ represent the effect of different cations. Figures 1a and 1c reveal that $\varepsilon$ ' increases with increasing temperature, independently of IL type, due to different contributions to the permittivity: $d c$ conductivity, electrode polarization, Maxwell-Wagner relaxation and charge motion and transport [43]. Further, Figure 1a demonstrates that the use of different anions while maintaining the same $[\mathrm{EMIM}]^{+}$ion leads to significant changes in the dielectric constant due to different charge transport characteristics. The increase in $\varepsilon^{\prime}$ with respect to PVDF is lowest in the case of $[\mathrm{Emim}]\left[\mathrm{HSO}_{4}\right]$ addition.
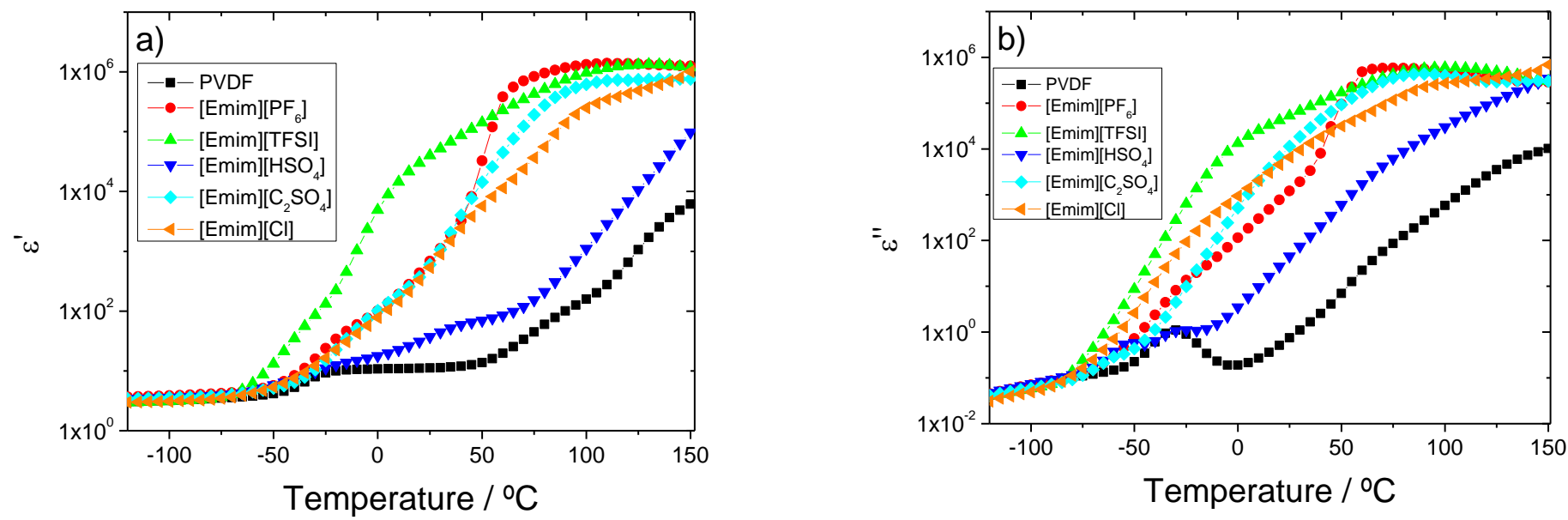

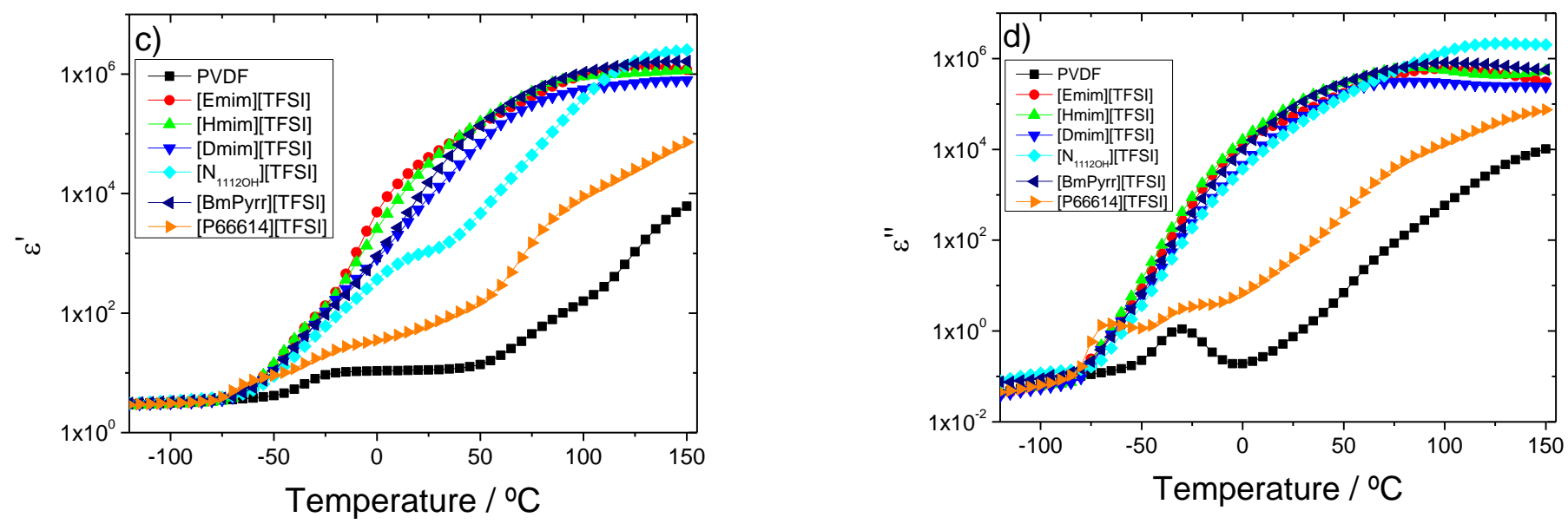

Figure 1 - Temperature dependence of $\varepsilon^{\prime}$ (a and c) and $\varepsilon^{\prime \prime}$ (b and d) measured at $100 \mathrm{~Hz}$ for the different PVDF/IL blends as a function of the different anions and cations.

For ILs containing the same anion but different cations (Figure 1c), the dielectric constant is practically the same for all PVDF/IL blends except for the blend incorporating [P66614][TFSI] that remains closer to the values of PVDF. Typically, IL with larger ions lead to an increase of viscosity and a decrease of ionic conductivity with respect to ILs with smaller ions. This effect is due to ion aggregation/pairing in which larger ion sizes cause the reduction of ion mobility and then the reduction of available charge carriers [44].

For neat PVDF, Figure 1 shows the process of the main dielectric relaxation associated with the glass transition of the amorphous phase ( $\beta$-relaxation) and then a rapid increase of both the real part $\varepsilon$ ' and the imaginary part $\varepsilon "$ of the permittivity that are associated with different movements that include relaxations involving crystallites and MaxwellWagner relaxation associated with the accumulation of free charge carriers at the interfaces between the amorphous and crystalline phases [45]. 
Due to the high conductivity of the PVDF/IL blends, after the $T_{g}$, the contribution of conductivity completely overshadows the contribution of dipolar movements and only the $\beta$-relaxation is revealed.

For blends comprising [Emim][HSO 4 and [P66614][TFSI], the main dipolar relaxation is detected despite the fact that the contribution of space charges is significantly larger than in net PVDF, because they are not as high as in the other PVDF/IL blends.

In order to describe the molecular dynamics of the PVDF/IL blends, the electric modulus formalism $\left(\mathrm{M}^{*}\right)$ can be used, since it eliminates conductivity contribution of the loss spectra and provides the dipolar relaxation mechanisms as shown in Figure 2.

For neat PVDF, two peaks in $\mathrm{M} "$ at -33 and $55^{\circ} \mathrm{C}$ are observed (Figures $2 \mathrm{a}$ and $2 \mathrm{c}$ ) that describe the $\beta$-relaxation and Maxwell-Wagner relaxation, respectively [45]. Independently of the IL type, Figures $2 \mathrm{a}$ and $2 \mathrm{c}$ show a peak for $\mathrm{M}$ " that describes the $\beta$ relaxation. Except for $\left[\right.$ Emim] $\left[\mathrm{HSO}_{4}\right]$ and $[\mathrm{P} 66614][\mathrm{TFSI}]$ blends, the second peak related to the Maxwell-Wagner relaxation is not observed due to the different conductivity of the amorphous and crystalline phases and to the overlap of the conductivity and interfacial polarization phenomena. The peak related with the $\beta$ relaxation is practically the same for ILs with different cations (Figure 2c), while ILs with different anions present the main dielectric relaxation at different temperatures (Figure 2a). 

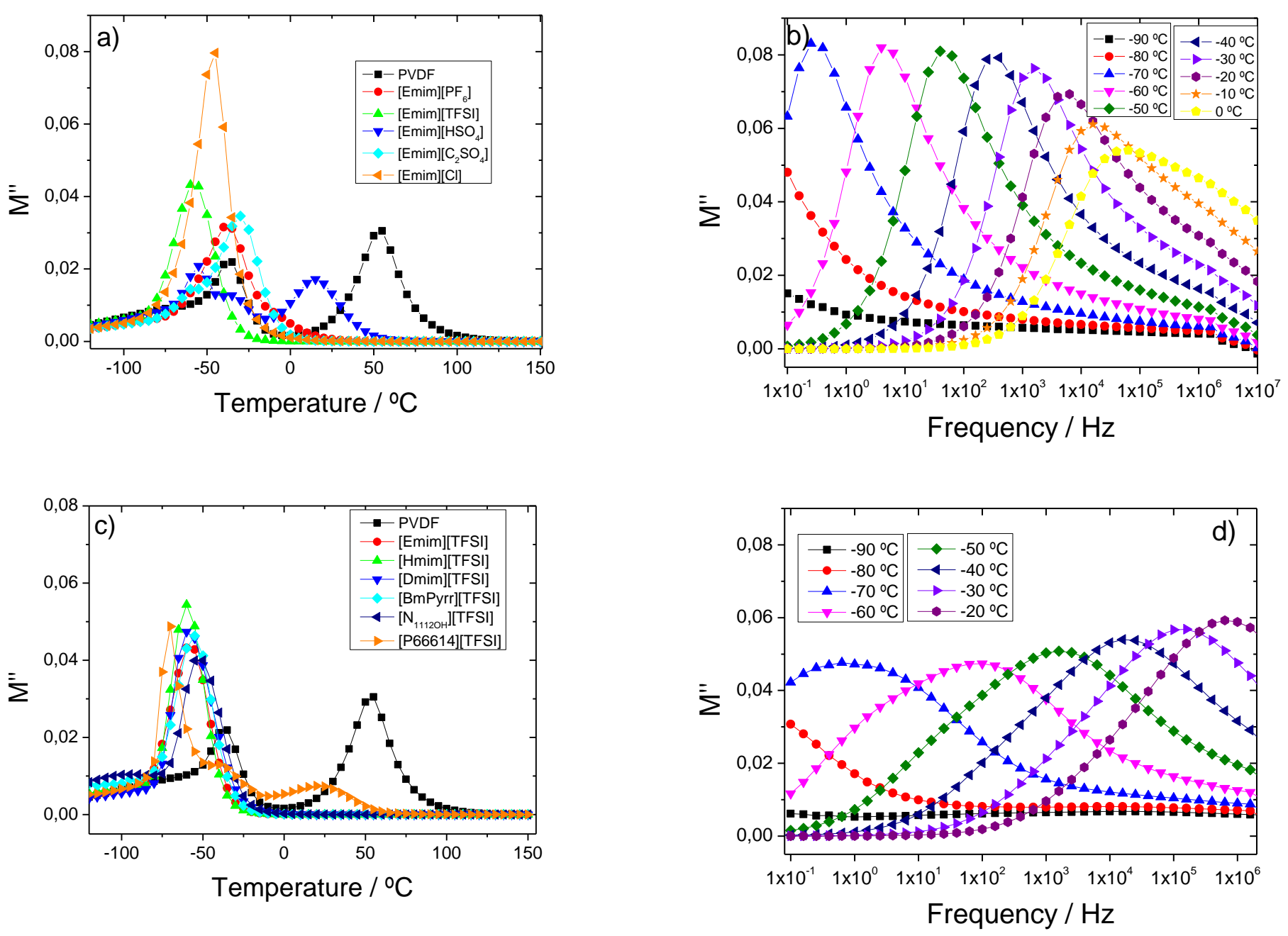

Figure 2 - a-c) Isochronal spectra at $100 \mathrm{~Hz}$ of the imaginary part of the electric modulus for the different PVDF/IL blends as a function of the different anion and cation, respectively. b-d) Frequency dependence of the imaginary part of the electric modulus from -90 to $-20^{\circ} \mathrm{C}$ for $[\mathrm{Emim}][\mathrm{Cl}]$ and $[\mathrm{Dmim}][\mathrm{TFSI}]$, respectively.

Figures $2 \mathrm{~b}$ and $2 \mathrm{~d}$ show the imaginary part of the complex modulus as a function of frequency for $[\mathrm{Emim}][\mathrm{Cl}]$ and $[\mathrm{Dmim}][\mathrm{TFSI}]$ blends between -90 and $10^{\circ} \mathrm{C}$, respectively. For other blends in the series of different anions and different cations (data not shown), the behavior is similar to those shown in the Figures $2 \mathrm{~b}$ and $2 \mathrm{~d}$. In this temperature range of the M" spectra, the observed peak, which corresponds to the $\beta$-relaxation, is shifted to higher frequencies with increasing temperature due to the increased segmental mobility 
of the polymer chains (it is to notice that for the temperatures of $-90{ }^{\circ} \mathrm{C}$ and $-80{ }^{\circ} \mathrm{C}$, the maximum of the relaxation is below the measured frequency range). An apparent relaxation time for the $\beta$-relaxation has been defined as the reciprocal frequency of the maximum of $M$ ' $\left(\tau_{M}=1 / \omega_{M}\right)$. The temperature dependence of the relaxation times for neat PVDF and PVDF/IL blends is depicted in Figure 3.

The dynamics of the $\beta$-relaxation observed for the PVDF/IL blends was analysed in the scope of the Vogel-Fulcher-Tammann (VFT) formalism:

$$
\tau_{M}(T)=\frac{1}{\omega_{M}}=\tau_{0} e^{\frac{B}{T-T_{0}}}
$$

where $\tau_{0}$ is the relaxation time for infinite temperature, $\mathrm{B}$ is a constant and $\mathrm{T}_{0}$ (Vogel temperature) is the temperature where all the chain motions in equilibrium are frozen (usually $30-70 \mathrm{~K}$ below $\mathrm{T}_{\mathrm{g}}$ ). The values obtained by fitting to the experimental data are listed in Table 2.

The dielectric transition temperature ( $\left.\mathrm{T}_{\text {g-diel }}\right)$ was obtained from eq. 4 for $\tau_{\mathrm{M}}=100 \mathrm{~s}$. The apparent activation energy of the process at the $\mathrm{T}_{\mathrm{g} \text {-diel }}$ was calculated from eq. 5 .

$$
E_{a}(T)=\frac{R \cdot B}{\left(1-\frac{T_{0}}{T}\right)^{2}}
$$

The fragility parameter $m$ (eq. 6) was calculated from the activation energy at $\mathrm{T}_{\mathrm{g} \text {-diel. }}$

$$
m=\frac{E_{a}\left(T_{g-d i e l}\right)}{\ln 10 \cdot R \cdot T_{g-d i e l}}
$$

where $m$ is an indication of the steepness of the variation of the material properties (viscosity, relaxation time, ...) as $T_{g}$ is reached. A high $m$ value defines a fragile material, 
whereas a strong material is characterized by small $m$ values [46]. The values of fragility and activation energy at $T_{g}$ are listed in Table 2.
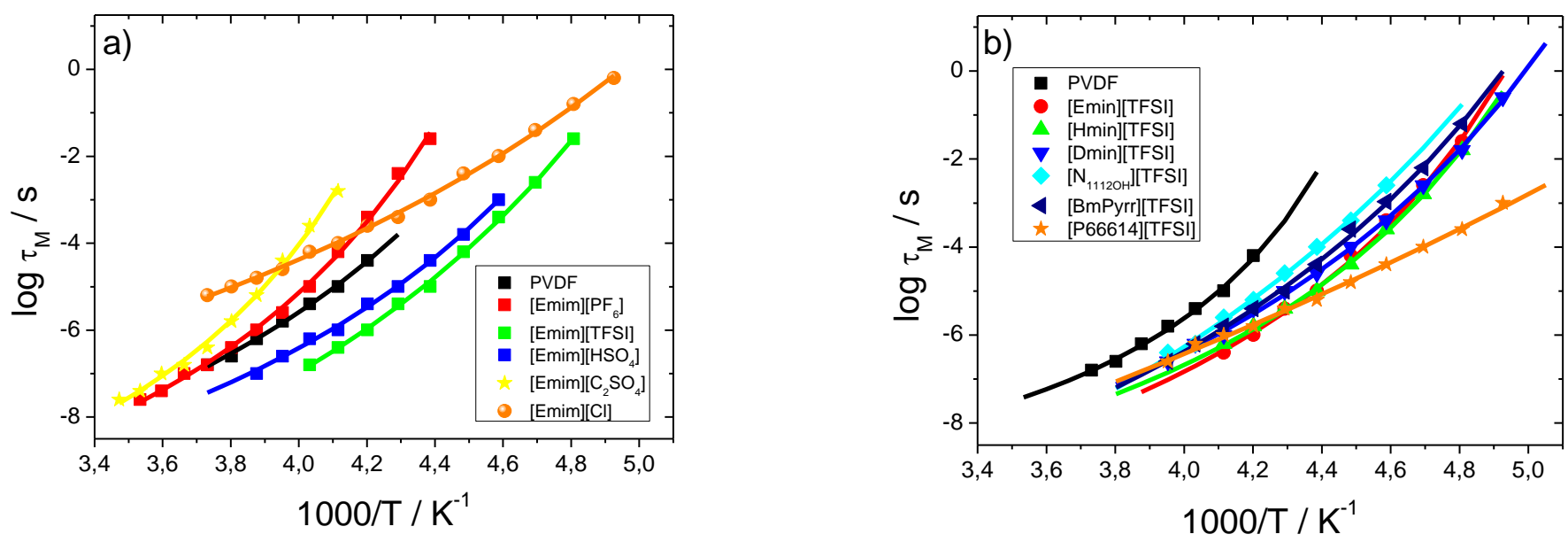

Figure 3 - Temperature dependence of the relaxation time of the structural $\beta$-relaxation of PVDF and PVDF/IL blends obtained from the maximum in M'' isotherms for different anions (a) and cations (b). Solid lines show VFT fitting.

Regardless of the IL type, Table 2 shows that the activation energy at $T_{g}$ and the fragility decrease with respect to pure PVDF. The main reason is due to high conductivity of the IL and ion-pair interactions [42]. The fragility presents particular values for each anion or cation. For example, for the same anion [TFSI]', but cations with increased length of the alkyl chain, i.e, [Emim] to [Dmim], fragility decreases. 
Table 2 - VFT fitting parameter and apparent activation energy for the structural $\beta$ relaxation of PVDF and PVDF/IL blends obtained from the maximum of M'.

\begin{tabular}{|c|c|c|c|c|c|c|c|c|}
\hline \multicolumn{2}{|r|}{ Sample } & $\mathrm{T}\left({ }^{\circ} \mathrm{C}\right)$ & $\tau_{0}(\mathrm{~s})$ & $\mathrm{B}(\mathrm{K})$ & $\mathrm{T}_{0}(\mathrm{~K})$ & $\begin{array}{c}\mathrm{E}_{\mathrm{a}}\left(\mathrm{KJmol}^{-1}\right) \\
\tau=100 \mathrm{~s}\end{array}$ & $\mathrm{~m}$ & $\begin{array}{c}\mathrm{T}_{\mathrm{g} \text {-diel }} \\
\left({ }^{\circ} \mathrm{C}\right) \\
\tau=100 \mathrm{~s}\end{array}$ \\
\hline & PVDF & {$[-5,-40]$} & $5.2 \mathrm{E}-11$ & 566 & 197 & 554 & 133 & -56 \\
\hline \multirow{5}{*}{ Anion } & {$[\mathrm{Emim}]\left[\mathrm{PF}_{6}\right]$} & {$[10,-55]$} & $1.9 \mathrm{E}-13$ & 1172 & 182 & 385 & 93 & -56 \\
\hline & {$[$ Emim] $][$ TFSI] } & {$[-25,-65]$} & $6.7 \mathrm{E}-13$ & 1037 & 166 & 333 & 88 & -76 \\
\hline & {$[\mathrm{Emim}]\left[\mathrm{HSO}_{4}\right]$} & {$[-5,-60]$} & 4.1E-13 & 1201 & 162 & 312 & 82 & -74 \\
\hline & {$[\mathrm{Emim}]\left[\mathrm{C}_{2} \mathrm{SO}_{4}\right]$} & {$[15,-50]$} & $2.7 \mathrm{E}-13$ & 998 & 198 & 511 & 117 & -44 \\
\hline & {$[$ Emim $][\mathrm{Cl}]$} & {$[-5,-70]$} & $2.2 \mathrm{E}-11$ & 1685 & 133 & 160 & 44 & -82 \\
\hline \multirow{6}{*}{ Cation } & [Emim] [TFSI] & {$[-25,-65]$} & $6.7 \mathrm{E}-13$ & 1037 & 166 & 333 & 88 & -76 \\
\hline & [Hmim][TFSI] & {$[-25,-65]$} & $2.3 \mathrm{E}-12$ & 963 & 166 & 327 & 87 & -77 \\
\hline & {$[$ Dmim] $]$ TFSI] } & {$[-20,-70]$} & $2.4 \mathrm{E}-13$ & 1412 & 152 & 250 & 68 & -79 \\
\hline & [BmPyrr][TFSI] & {$[-20,-70]$} & $4.1 \mathrm{E}-14$ & 1593 & 151 & 252 & 67 & -77 \\
\hline & {$\left[\mathrm{N}_{1112 \mathrm{OH}}\right][\mathrm{TFSI}]$} & {$[-20,-65]$} & $5.8 \mathrm{E}-16$ & 2279 & 140 & 223 & 59 & -76 \\
\hline & [P66614][TFSI] & {$[-20,-70]$} & $3.1 \mathrm{E}-16$ & 3664 & 74.8 & 101 & 32 & -107 \\
\hline
\end{tabular}

The existence of different electrical processes/contributions is revealed even more clearly in the Cole-Cole arcs in which $\mathrm{M}$ " is plotted against $\mathrm{M}$ ' in the temperature range between -120 to $150^{\circ} \mathrm{C}$ as it is shown in Figure 4.
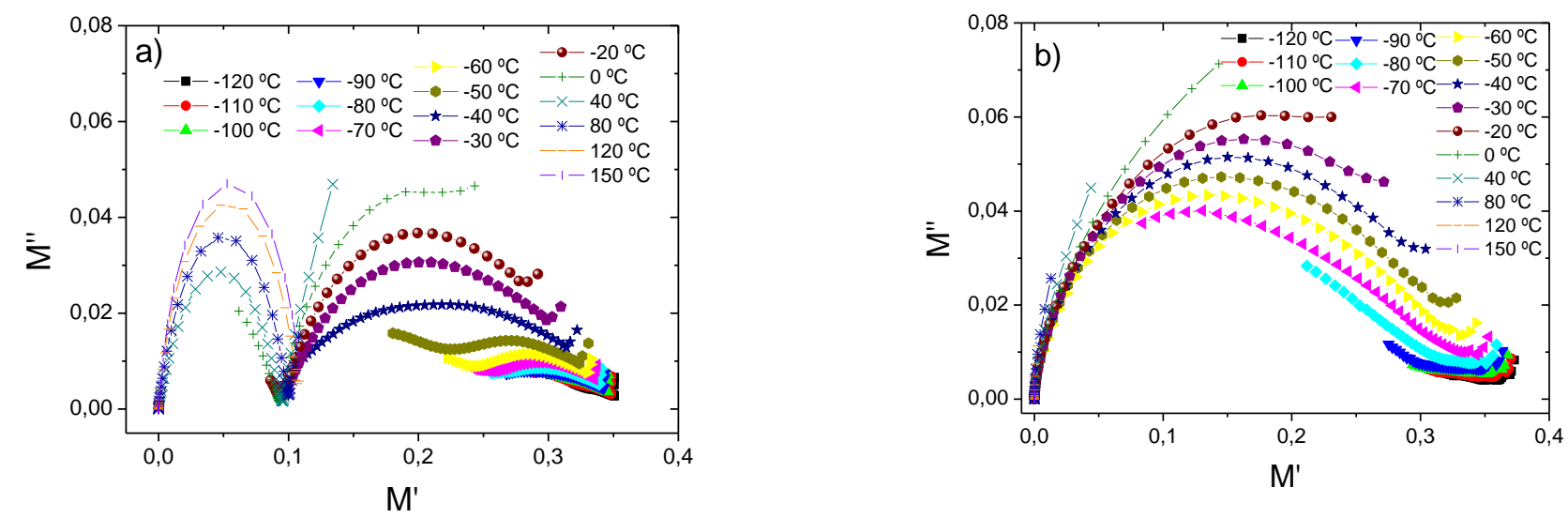

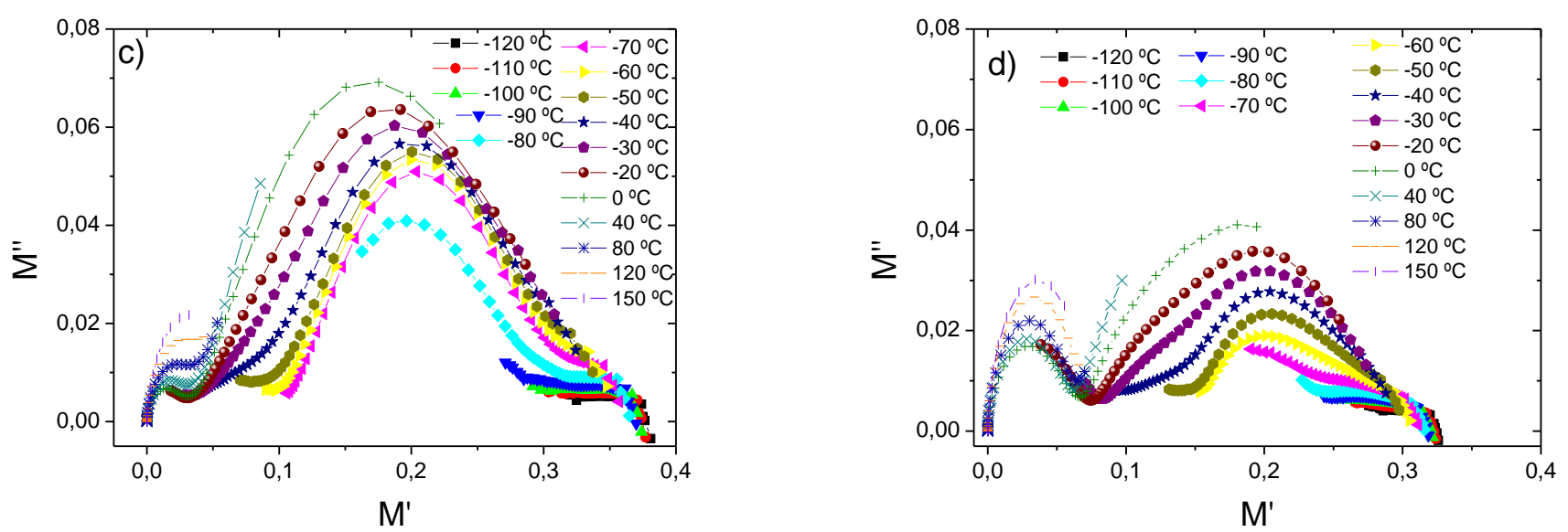

Figure 4 - Cole-Cole plots of the electric modulus for neat PVDF (a), [Emim][TFSI] (b), [P66614][TFSI] (c) and [Emim][HSO 4$]$ (d).

Figure 4 shows only Cole-Cole arcs for neat PVDF and [Emim][TFSI], [P66614][TFSI] and $[$ Emim $]\left[\mathrm{HSO}_{4}\right]$ blends. These graphs demonstrate the effect of the anion and cation of the IL. Cole-Cole arcs for other PVDF/IL blends are similar to those observed in Figure 4b. Figure 4a for neat PVDF shows two arcs corresponding to the $\beta$-relaxation and Maxwell-Wagner process. This fact is also found for blends containing [P66614][TFSI] (Figure 4c) and [Emim][HSO 4 (Figure 4d). For the PVDF/[Emim][TFSI] blend, as in the rest of blends showing a single relaxation peak in M', shows only a single arc in the relaxation process (Figure $4 \mathrm{~b}$ ) that suggests the presence of dipolar relaxation. For all PVDF/IL blends, the interval of M' covering the set of relaxation processes is very similar independently of the different anion and cation in the IL. 


\subsection{Conductivity formalism}

The formalism of electrical conductivity can be obtained from the dielectric spectrum using equation 3. Considering the high conductivity of ILs, this formalism has particular relevance to distinguish the different processes in the PVDF/IL blends, such as electrode polarization, $a c$ and $d c$ conductivity.

Figure 5 shows the real and imaginary parts of the $\sigma^{*}(\omega)$ for neat PVDF and for PVDFbased $[$ Emim] $][\mathrm{TFSI}],[\mathrm{BmPyrr}][\mathrm{TFSI}]$ and $[\mathrm{Emim}]\left[\mathrm{HSO}_{4}\right]$ blends. For other PVDF/IL blends, the conductivity formalism reveals similar results.

For neat PVDF (Figures 6a-b), $\sigma^{\prime}(\omega)$ increases with increasing frequency for all temperatures. Also, for neat PVDF, a plateau in $\sigma^{\prime}(\omega)$ that describes the $d c$ conductivity is observed, being broader as temperature increases.

In the PVDF/IL blends, the $\sigma^{\prime}$ plot presents, from low to high frequencies, the initial increase due to the blocking effect of the charge carriers [47], the plateau due to $d c$ conductivity $\left(\sigma_{0}\right)$ and the linear increase due to $a c$ conductivity.

For the PVDF/IL blends, a peak in $\sigma^{\prime \prime}$ is observed, with increasing strength and shifting towards higher frequencies as temperature increases, caused by the electrode polarization [48]. The electrode polarization is due to the accumulation of ionic charge carriers at the electrode-sample interface [49]. The shape of this peak is not the same for the different anions and cations in PVDF/IL blends, reflecting a different conductivity behaviour as shown in Figure 5. The main reason for this fact is related to the different anion and cation size that affects the electrode polarization. 

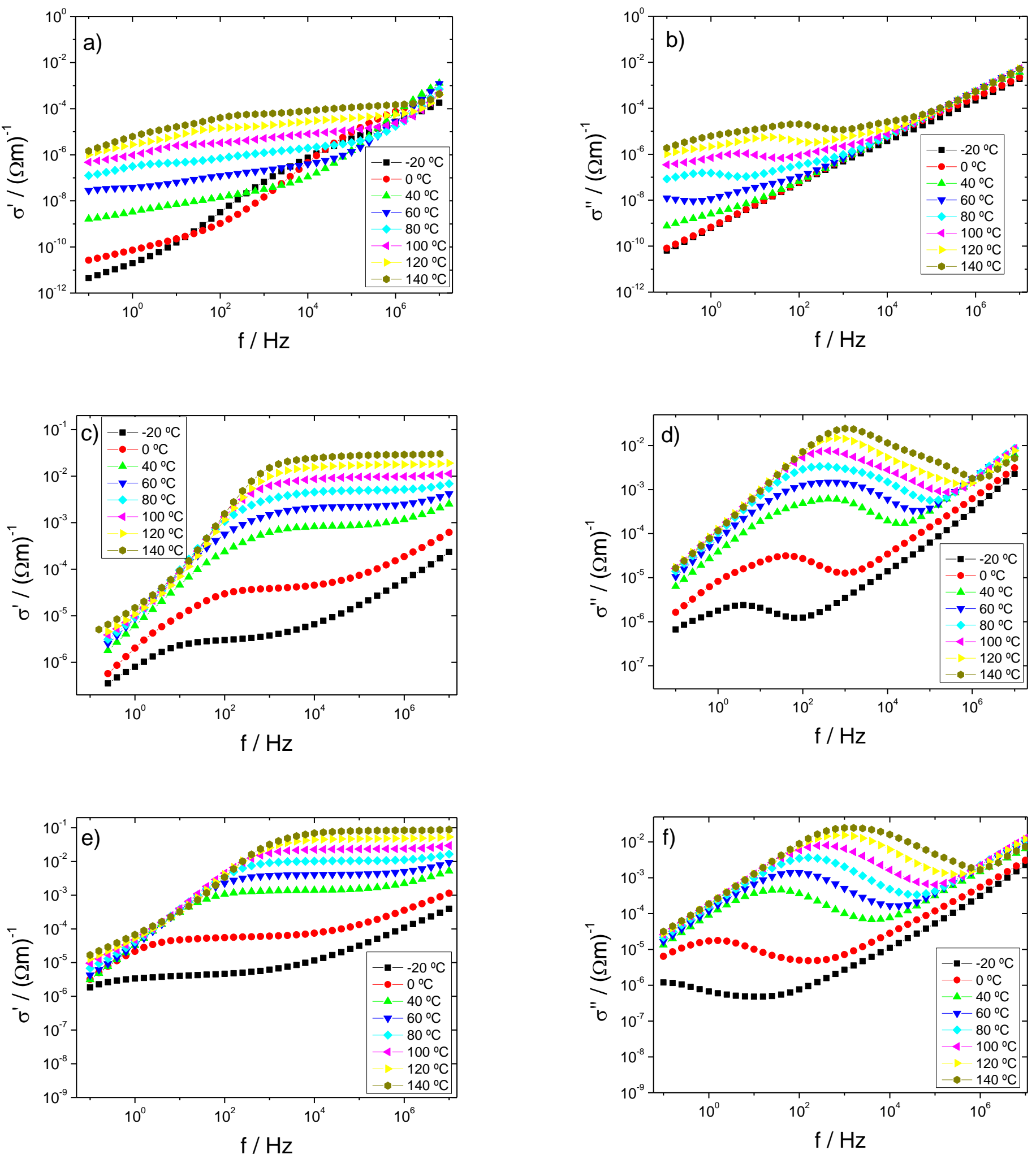

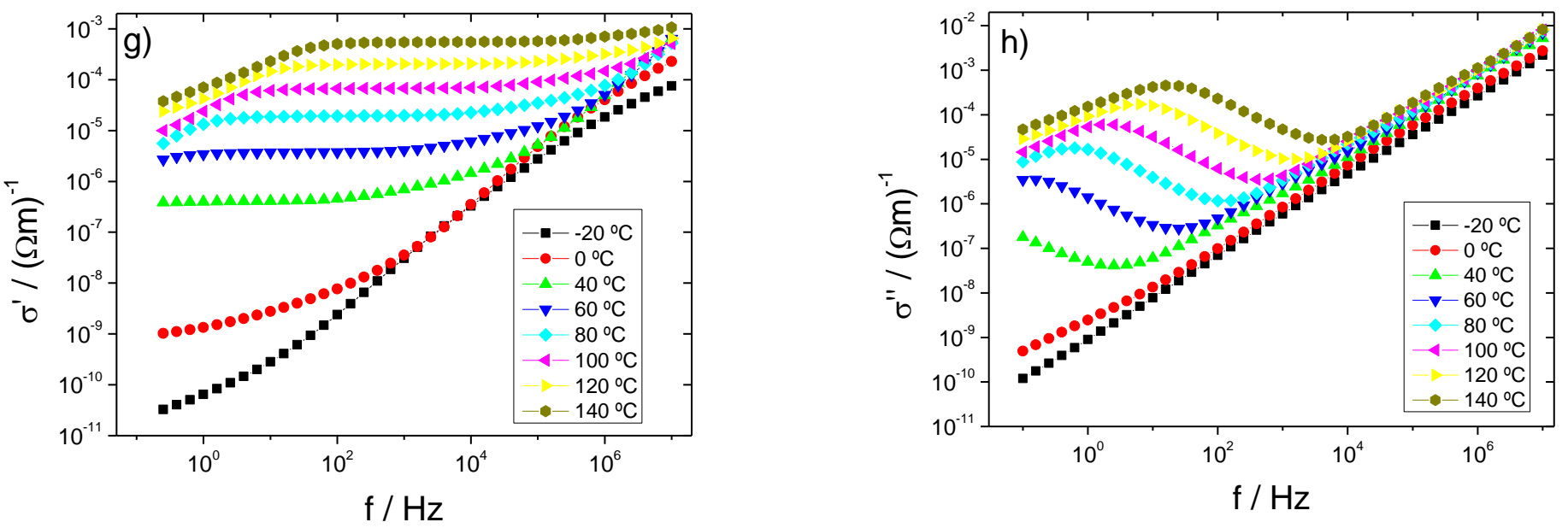

Figure 5 - Frequency dependence of the real and imaginary part of the conductivity $\left(\sigma^{*}\right)$ at different temperatures for neat PVDF $(a, b),[$ Emim] [TFSI] $(c, d)$ and [BmPyrr][TFSI] $(\mathrm{e}, \mathrm{f})$ and $[\mathrm{Emim}]\left[\mathrm{HSO}_{4}\right](\mathrm{g}, \mathrm{h})$.

Considering the time-temperature superposition principle [50], it was possible to derive a single master curve through the isotherms $\sigma^{\prime}$ normalized with respect to $\sigma_{0}$ and to the characteristic frequency $\left(\omega_{c}\right)$ at which the real part of the conductivity begins to increase with frequency, i.e. the onset of $a c$ conductivity that corresponds to the intersection of the $a c$ conductivity straight line with the horizontal plateau in the $\log \left(\sigma^{\prime}\right)$ vs $\log (\omega)$ plot. Nevertheless, as this extrapolation is quite uncertain, the value of $\omega_{\mathrm{c}}$ for each temperature is determined more precisely considering it as a fitting parameter in the master curve construction. The master curves $\log \left(\sigma^{\prime} / \sigma_{0}\right)$ vs $\log \left(\omega / \omega_{c}\right)$ are shown in Figure 6 . In the inset of Figure 6 , the relation between the value of $\omega_{c}$, calculated in this way, and the characteristic frequency $\omega_{M}=1 / \tau_{M}$, obtained from the maximum of $M$ " as a function of temperature, are shown. 

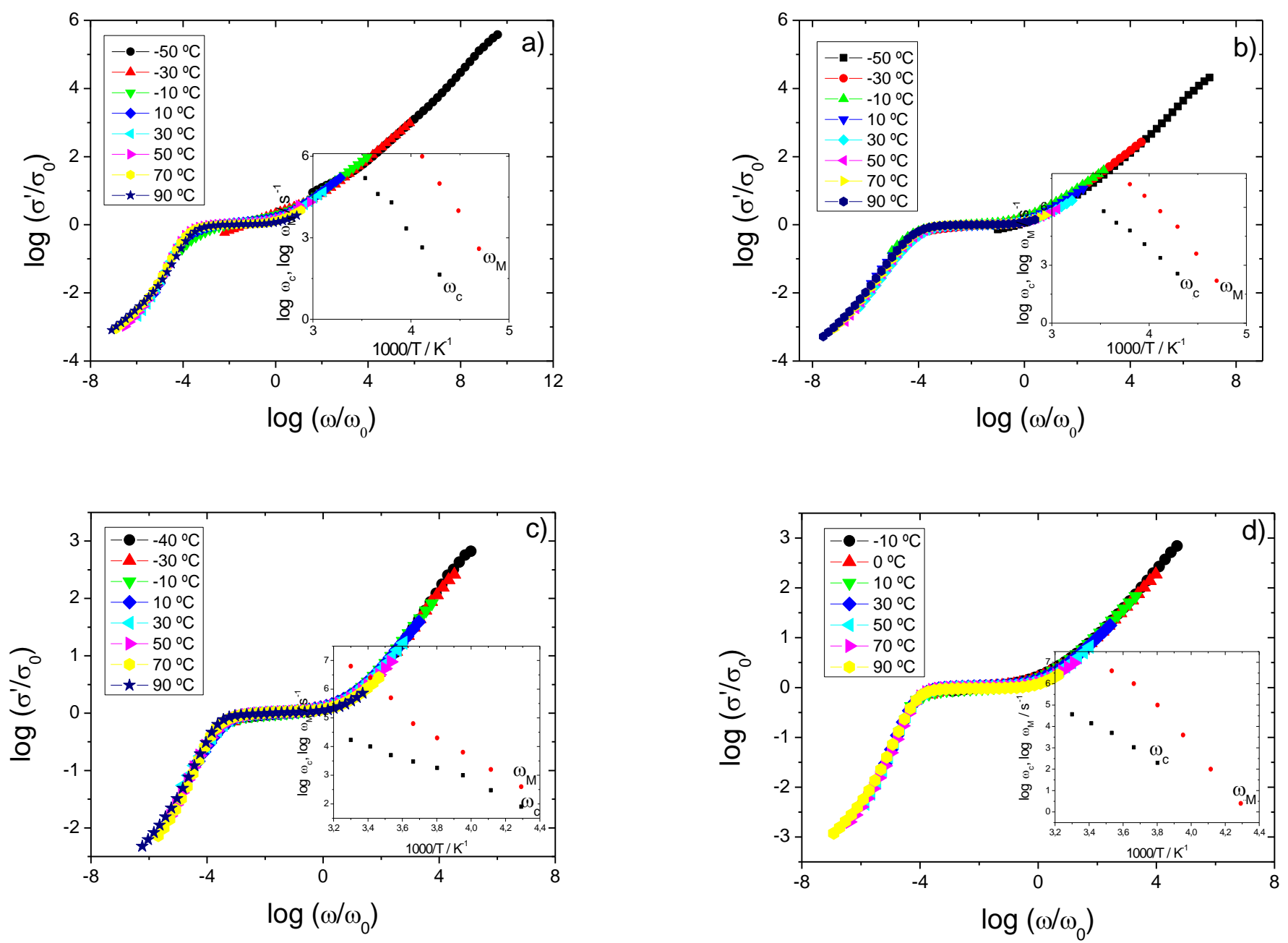

Figure 6 - Scaling with respect to the characteristic frequency, $\omega_{c}$, and dc-conductivity, $\sigma_{0}$, for different temperatures. a) [Dmim][TFSI], b) $[\mathrm{BmPyrr}][\mathrm{TFSI}]$, c) $[\mathrm{Emim}][\mathrm{Cl}]$ and $[$ Emim $]\left[\mathrm{C}_{2} \mathrm{SO}_{4}\right]$. Inset: Temperature dependence of the characteristic frequency $\omega_{\mathrm{M}}$ obtained from M', and $\omega_{c}$.

Figure 6 shows the master curves for the [Dmim][TFSI], [BmPyrr][TFSI], [Emim][Cl] and $[$ Emim $]\left[\mathrm{C}_{2} \mathrm{SO}_{4}\right]$. It was possible to obtain the master curves as in Figure 6 for all PVDF/IL blends except for the [THTDP][TFSI] blend and neat PVDF.

For all PVDF/IL blends, two spectral regions are observed, related to different phenomena, i.e, electrode polarization at low frequency, and ac conductivity at high frequency separated by the $d c$ plateau. 
For the different ILs, the initiation of $a c$ conductivity is directly related to the conformational mobility of the system. For the PVDF/IL blends (inset of Figure 6), the displacement between the values of $\omega_{c}$ and $\omega_{M}$ indicate that this is not observed.

Temperature dependence of $d c$ conductivity $\sigma_{0}$ exhibits a Vogel-Fulcher-Tammann (VFT) dependence (Figure 7), typical for glass-forming liquids and can be adjusted through the following equation:

$$
\sigma_{0}(T)=\sigma_{\infty} e^{\frac{B^{\prime}}{T-T_{0}}}
$$

where $\sigma_{\infty}$ is the $d c$ conductivity for infinite temperature, $B$ ' is a constant and $T_{0}$ is the Vogel temperature.
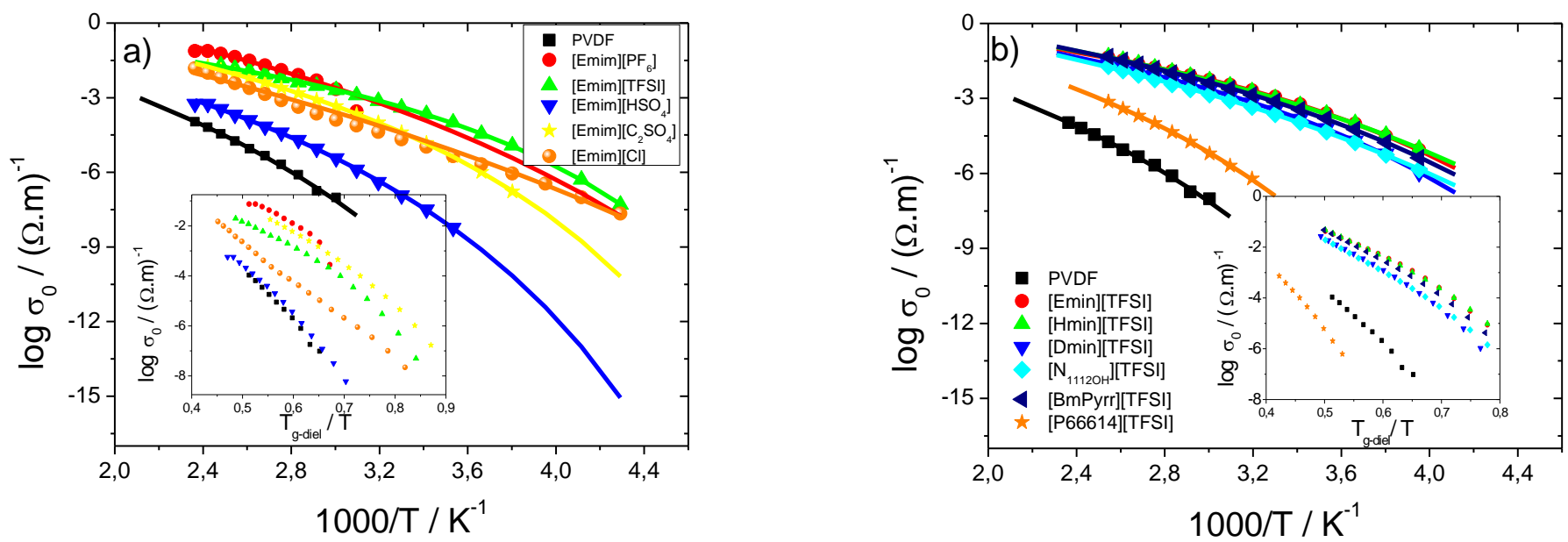

Figure 7 - Temperature dependence of $d c$ conductivity, $\sigma_{0}$, of PVDF and PVDF/IL blends as a function of the different anions (a) and cations (b). Solid lines show VFT fitting (Inset: scaling with respect to the dielectric $\mathrm{Tg} T_{g-\text { diel }}$ ). 
The solid lines in Figure 7 show the good agreement between experimental results and VTFH fitted for all PVDF/IL blends over a wide temperature range. The fitting parameters are presented in Table 3 . This Table shows that $T_{0}$ decreases for the PVDF/IL blends in comparison to neat PVDF except for the [P66614][TFSI] blend.

Table 3 - VFT fitting parameters obtained for $d c$ conductivity, $\sigma_{0}$, of PVDF and PVDF/IL blends

\begin{tabular}{|c|c|c|c|c|c|}
\hline & Sample & $\begin{array}{l}\text { Temperature } \\
\text { interval }\left({ }^{\circ} \mathrm{C}\right)\end{array}$ & $\sigma_{\infty}(\Omega \mathrm{m})^{-1}$ & $\mathbf{B}^{\prime}(\mathrm{K})$ & $\mathbf{T}_{0}(\mathbf{K})$ \\
\hline & PVDF & {$[60,150]$} & 47 & -3232 & 174 \\
\hline \multirow{5}{*}{ Anion } & {$[\mathrm{Emim}]\left[\mathrm{PF}_{6}\right]$} & {$[50,150]$} & 768 & -2625 & 126 \\
\hline & {$[$ Emim] $]$ TFSI] } & {$[-40,140]$} & 15.9 & -1417 & 155 \\
\hline & {$[\mathrm{Emim}]\left[\mathrm{HSO}_{4}\right]$} & {$[10,150]$} & 20 & -2636 & 163 \\
\hline & {$[\mathrm{Emim}]\left[\mathrm{C}_{2} \mathrm{SO}_{4}\right]$} & {$[-10,140]$} & 48 & -2004 & 160 \\
\hline & {$[$ Emim $][\mathrm{Cl}]$} & {$[-40,150]$} & 129 & -3109 & 96 \\
\hline \multirow{6}{*}{ Cation } & {$[$ Emim] $][$ TFSI] } & {$[-20,120]$} & 15.9 & -1417 & 155 \\
\hline & [Hmim][TFSI] & {$[-20,120]$} & 44.5 & -1765 & 138 \\
\hline & [Dmim][TFSI] & {$[-20,120]$} & 26.7 & -1678 & 154 \\
\hline & [BmPyrr][TFSI] & {$[-20,120]$} & 71.8 & -1874 & 140 \\
\hline & {$\left[\mathrm{N}_{1112 \mathrm{OH}}\right][\mathrm{TFSI}]$} & {$[-20,120]$} & 104 & -2342 & 123 \\
\hline & [P66614][TFSI] & {$[40,120]$} & 143 & -2657 & 176 \\
\hline
\end{tabular}

Figure 8 shows the $d c$ conductivity $\left(\sigma_{0}\right)$ as a function of the characteristic frequency, $\omega_{\mathrm{c}}$ for different anions (Figure 8a) and different cations (Figure 8b). For all PVDF/IL blends, it is observed that the glassy dynamics enhances charge transport in ILs ionic liquids. This implies the Barton-Namikawa-Nakajima $(\mathrm{BNN})$ relation $\left(\sigma_{0} \sim \omega_{\mathrm{c}}\right)$, as it is evident in Figure 8 [51]. The characteristic linear relationship between $\sigma_{0}$ and $\omega_{c}$ is observed, but the overlap for the different ILs is not complete, and the values corresponding to $[$ Emim $]\left[\mathrm{HSO}_{4}\right]$ are closer to pure PVDF than to the other blends. 

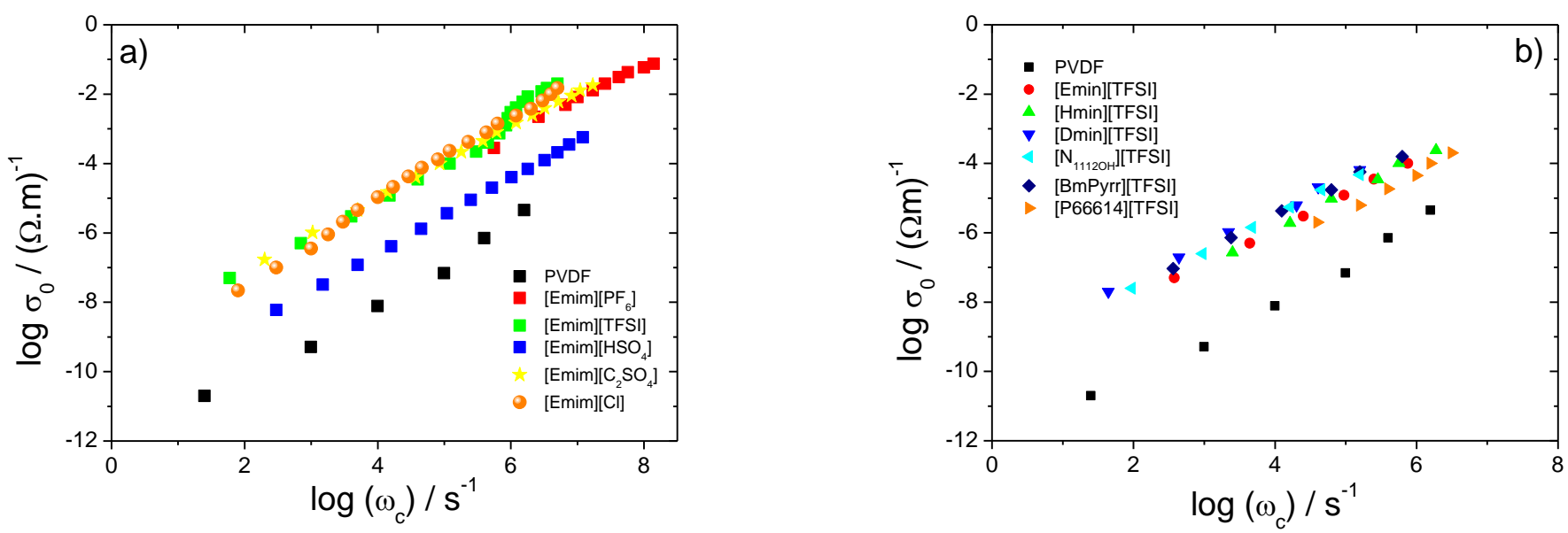

Figure 8 - Dc conductivity, $\sigma_{0}$, vs the characteristic frequency, $\omega_{c}$ for different anions (a) and cations (b).

Charge transport in ILs has been described by a mechanism assisted by hopping process [49]. The determination of the activation energy of $a c$ conductivity has been performed following the Dyre model through the following equation [52]:

$$
\sigma_{a c}(T)=B e^{-\frac{E_{a}}{k_{B} T}}
$$

where $B$ is a pre-exponential factor identified as the attempt frequency, $E_{a}$ is the apparent activation energy of the process, $T$ is temperature and $k_{B}$ is the Boltzmann constant. For the activation energy calculation, only data points in the region of the linear relationship between $\log \sigma^{\prime}$ and $\log \omega$ were used. The frequency interval corresponding to this regime depends on temperature as shown in figure 5.

Figure 9 shows that for the PVDF/IL blends there is a sharp reduction of the activation energy of the process for all frequencies in comparison to neat PVDF. 

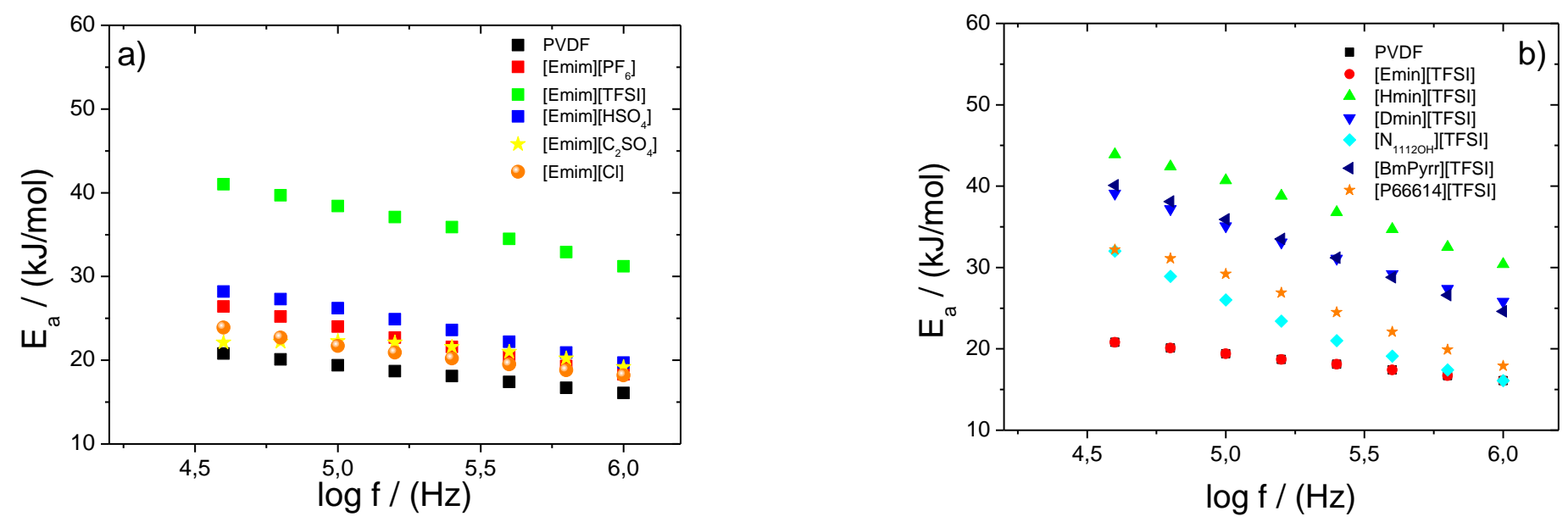

Figure 9 - Apparent activation energy of the all PVDF/IL blends for different anions (a) and cations (b) obtained after fittings with the Dyre model.

\section{Discussion}

ILs are glass-forming liquids with low $\mathrm{T}_{\mathrm{g}}$ [32]. Their ionic conductivity has been studied in detail by the combination of DRS, NMR, viscosity measurements and calorimetry techniques [34-37], indicating that the dynamics of the displacement of electric charge carriers is dominated by the conformational mobility and glass transition of the glass forming substance, and its viscoelastic behavior.

When the homogeneous mixture of the IL with the polymer chain segments is in the amorphous phase, the scenario changes because the conformational mobility and the glass transition is no longer governed just by the IL. This is the case in the blends of PVDF and ILs as observed by the shift of the main dielectric relaxation, $\beta$, of the amorphous phase of the PVDF towards low temperatures due to the plasticizing effect of the IL (Table 2). At the same time, the temperature range in which the relaxation occurs widens, as can be observed in Figures $2 \mathrm{a}$ and $2 \mathrm{c}$ in the formalism of the dielectric module, what is the behaviour that can be expected in the homogeneous mixtures in which at least one of the components is a polymer. This behaviour is particularly clear in the series of mixtures 
with ILs with different cations and [TFSI] ${ }^{-}$as the anion. However, in mixtures of ILs that have $[\text { Emim }]^{+}$as the cation and different anions the behaviour is more different from one anion to another. This different behaviour is also observed in the width of the relaxation peak in the $M$ " vs frequency plots. Figures $2 \mathrm{~b}$ and $2 \mathrm{~d}$ shows these plots in two mixtures $[$ Emim $][\mathrm{Cl}]$ and $[$ Dmim] $[$ TFSI], representative of the two series, being the peak narrower and more asymmetric in the former.

The exceptions to the miscibility between PVDF and ILs in the amorphous phase are the blends of PVDF with [P66614][TFSI] and [Emim] $\left[\mathrm{HSO}_{4}\right]$. In the former case, Figure 2 shows the presence of two peaks in $M^{\prime \prime}$, one of them at the same temperature than PVDF while the other one is at much lower temperatures, thus corresponding to two amorphous phases one of them rich in amorphous PVDF chain segments and the other one rich in the IL. In the case of $[\mathrm{Emim}]\left[\mathrm{HSO}_{4}\right]$ two peaks appear as well in the temperature interval between -75 and $-20{ }^{\circ} \mathrm{C}$ (Figure $2 \mathrm{a}$ ). The presence of two relaxation processes in the region of the main dielectric relaxations is still clearer in the Cole-Cole arcs of Figures $4 c$ and $4 \mathrm{~d}$, respectively. Phase separation in these two blends will make the whole behaviour relative to ionic conductivity of these two blends different than that of the other blends of their series.

It can be stated that the interaction between the IL and the segments of the PVDF chains is governed by the anion of the IL, since it presents certain particularities for the different anions, while being nearly independent of the cation. The different size of the anions in the series with $[\mathrm{Emim}]^{+}$as the cation, can also play an important role in charge carrier motions.

The ionic conductivity behaviour in all blends maintains the main characteristics of pure ILs. The shape of the isothermal curves of $\sigma^{\prime}$ and $\sigma^{\prime}$ ' corresponds in everything to what is found in pure ILs: from low to high frequencies several contributions appear: the 
electrode polarization, the $d c$ conductivity plateau $\left(\sigma_{0}\right)$ and the region of the $a c$ conductivity in which $\log \sigma^{\prime}$ grows approximately linearly with frequency. The frequency of the transition between the plateau and the $a c$ conductivity is $\omega_{c}$, which has been related in pure ILs to the frequency with which the jump of the energy barrier that opposes the transport of electric charge [53].

It is worth noticing, first of all, the dependence of the $d c$ conductivity $\sigma_{0}$ with temperature, following a VFT ratio with values between 3 and 4 orders of magnitude above that of pure PVDF in the mixtures in which the IL and the PVDF are miscible in the amorphous phase. However, in the two mixtures that present phase separation, the $d c$ conductivity shows much lower values than the rest of the mixtures (Figure 7).

The $\tau_{0}$ parameter for all PVDF/IL blends decreases in comparison to that of neat PVDF except for $[\mathrm{Emim}][\mathrm{Cl}]$ due to the plasticizing effect of $\mathrm{IL}$ and the values are typical for values of non-cooperative Debye processes originated by local orientational fluctuations [54]. This fact can be attributed to the dispersion of a large part of the ions in isolated domains dispersed in the non-conductive matrix of PVDF when phase separation occurs. It is also indicative that when the amorphous phase is a homogeneous mixture of the IL and the PVDF chains, this phase has sufficient continuity to allow macroscopic displacement of the charge carriers despite the presence of the PVDF crystalline structure. It was possible to construct master curves for both $\sigma^{\prime}$ and $\sigma^{\prime}$ ' representing $\log \left(\sigma^{\prime} / \sigma_{0}\right)$ diagrams versus $\log \left(\omega / \omega_{c}\right)$ as shown in Figure 6 . The possibility of drawing a master curve for $\sigma^{\prime}$ in the whole frequency range means that both the electrode polarization and the ionic conduction have the same temperature dependence and indicates that they can be governed by the same mechanism. In pure ILs it was shown that the value of $\omega_{c}$ approximately agrees with the frequency of the maximum of $M$ ' $[35,43]$, but this is not the case in the blends of the IL with PVDF, as shown in the insets of Figure 6. This 
difference could be associated with the fact that M" peaks are quite broad, even 7 frequency decades, as shown in Figures $2 b$ and $2 d$ in the case of the blends. In fact, the position of the maximum could not have a clear physical interpretation in this case.

It is interesting to note how the $\mathrm{T}_{\mathrm{g}}$, as defined above, determined from the dependence on $\omega_{\mathrm{c}}$ (Table 2), allows scaling the $d c$ conductivity of the series with different cations as shown in the insets of Figure 7b (with the exception of [P66614][TFSI] that presents phase separation). However, the same does not occur in the series including ILs with the same cation and different anions (figure 7a). Something similar occurs with the activation energy of the Dyre model (Figure 9). These results reinforce the idea that the particular interaction of each anion with the chain segments of the PVDF governs the displacement of the charge carriers in the ionic conduction.

\section{Conclusions}

Broadband dielectric spectroscopy (BDS) measurements of PVDF/IL blends with different types of ILs was used to determine the influence of different anions and cations of IL on the polymer's segmental dynamics and conductivity behavior. This is particularly interesting for the use of these materials in energy and sensor/actuator applications.

Two series of blends were studied one with different anions keeping same cation and the other one with different cations keeping same anion.

PVDF is a semi-crystalline polymer. The ILs is incorporated into the amorphous phase of the PVDF formed, in almost all the blends, a homogeneous mixture as demonstrated by the presence of a single dielectric main relaxation, $\beta$, shifted towards low temperatures with respect to the $\beta$ relaxation of pure PVDF. There are two exceptions in which it is seen that the IL remains in separate domains. 
When the mixture of IL and PVDF in the amorphous phase is homogeneous, the behavior in terms of the mobility of ionic carriers retains many of the properties of ionic conduction in pure ILs such as $d c$ conductivity values much higher than those of pure PVDF, a dependence of the conductivity with temperature according to VFT equation, and the possibility of constructing master curves for the complex conductivity or the relationship between $\sigma_{0}$ and $\omega_{c}$ according to the BNN equation. The presence of PVDF chain assortments mixed with the IL produced certain changes in the behavior with respect to the pure ILs. In particular the main relaxation became very broad and the frequency of the maximum of $M$ " is not coincident with $\omega_{c}$ as occurs in pure ILs. Interestingly, the behavior of blends with ILs with different cations is very similar to each other, while the different anions present more particular values of conductivity and mobility parameters. This is related to the different size of the ions and the interaction between anions and PVDF chain segments.

The amorphous phase mixture of PVDF and IL, in spite of the presence of the PVDF crystals, is continuous and allows the macroscopic displacement of charge carriers.

When there is no miscibility between the IL and the PVDF in the amorphous phase, the $d c$ conductivity is much lower than in the other mixtures, the ions are isolated, and their macroscopic displacement cannot take place.

\section{Acknowledgements}

This work was supported by the Portuguese Foundation for Science and Technology (FCT) in the framework of the Strategic Funding UID/FIS/04650/2013 and the Associated Laboratory Research Unit for Green Chemistry, Technologies and Clean Processes, LAQV (financed by national funds from FCT/MEC, UID/QUI/50006/2013 and ERDF under the PT2020, POCI-01-0145-FEDER-007265). The authors thank FEDER funds through the COMPETE 2020 Programme and National Funds through FCT 
under the projects PTDC/CTM-ENE/5387/2014, PTDC/EEI-SII/5582/2014 and PTDC/FIS-MAC/28157/2017. D.M.C., C.M.C., J.M.S.S.E. and P.M.R. also thank to the FCT for grants SFRH/BPD/121526/2016 and SFRH/BPD/112547/2015, and Investigator FCT contracts IF/00355/2012 and IF/0621/2015, respectively. Financial support from the Spanish Ministry of Economy and Competitiveness (MINECO) through the project MAT2016-76039-C4-(1 and 3)-R (AEI/FEDER, UE) (including the FEDER financial support) and from the Basque Government Industry and Education Departments under the ELKARTEK, HAZITEK and PIBA (PIBA-2018-06) programs, respectively, are acknowledged. CIBER-BBN is an initiative funded by the VI National R\&D\&I Plan 2008-2011, Iniciativa Ingenio 2010, Consolider Program. CIBER Actions are financed by the Instituto de Salud Carlos III with assistance from the European Regional Development Fund.

\section{References}

[1] Y.-S. Ye, J. Rick, B.-J. Hwang, Ionic liquid polymer electrolytes, Journal of Materials Chemistry A 1(8) (2013) 2719-2743.

[2] D.M. Correia, P. Martins, M. Tariq, J.M.S.S. Esperança, S. Lanceros-Méndez, Lowfield giant magneto-ionic response in polymer-based nanocomposites, Nanoscale 10(33) (2018) 15747-15754.

[3] J.C. Dias, M.S. Martins, S. Ribeiro, M.M. Silva, J.M.S.S. Esperança, C. Ribeiro, G. Botelho, C.M. Costa, S. Lanceros-Mendez, Electromechanical actuators based on poly(vinylidene fluoride) with [N1 $1112(\mathrm{OH})][\mathrm{NTf} 2]$ and [C2mim] [C2SO4], Journal of Materials Science 51(20) (2016) 9490-9503.

[4] R. Leones, C.M. Costa, A.V. Machado, J.M.S.S. Esperança, M.M. Silva, S. LancerosMéndez, Development of solid polymer electrolytes based on poly(vinylidene fluoridetrifluoroethylene) and the $\left[\begin{array}{lllll}\mathrm{N} 1 & 1 & 1 & 2(\mathrm{OH})\end{array}[\mathrm{NTf} 2]\right.$ ionic liquid for energy storage applications, Solid State Ionics 253 (2013) 143-150. 
[5] C. Liang, C.-Y. Yuan, R.J. Warmack, C.E. Barnes, S. Dai, Ionic Liquids: A New Class of Sensing Materials for Detection of Organic Vapors Based on the Use of a Quartz Crystal Microbalance, Analytical Chemistry 74(9) (2002) 2172-2176.

[6] R. Mejri, J.C. Dias, S. Besbes Hentati, G. Botelho, J.M.S.S. Esperança, C.M. Costa, S. Lanceros- Mendez, Imidazolium-based ionic liquid type dependence of the bending response of polymer actuators, European Polymer Journal 85 (2016) 445-451.

[7] R. Mejri, J.C. Dias, S.B. Hentati, M.S. Martins, C.M. Costa, S. Lanceros-Mendez, Effect of anion type in the performance of ionic liquid/poly(vinylidene fluoride) electromechanical actuators, Journal of Non-Crystalline Solids 453 (2016) 8-15.

[8] J.-M. Tarascon, Key challenges in future Li-battery research, Philosophical Transactions of the Royal Society A: Mathematical,

Physical and Engineering Sciences 368(1923) (2010) 3227-3241.

[9] S.B. Aziz, T.J. Woo, M.F.Z. Kadir, H.M. Ahmed, A conceptual review on polymer electrolytes and ion transport models, Journal of Science: Advanced Materials and Devices 3(1) (2018) 1-17.

[10] L. Yue, J. Ma, J. Zhang, J. Zhao, S. Dong, Z. Liu, G. Cui, L. Chen, All solid-state polymer electrolytes for high-performance lithium ion batteries, Energy Storage Materials 5 (2016) 139-164.

[11] L. Long, S. Wang, M. Xiao, Y. Meng, Polymer electrolytes for lithium polymer batteries, Journal of Materials Chemistry A 4(26) (2016) 10038-10069.

[12] K.S. Ngai, S. Ramesh, K. Ramesh, J.C. Juan, A review of polymer electrolytes: fundamental, approaches and applications, Ionics 22(8) (2016) 1259-1279.

[13] D.T.H. Jr., N.P. Balsara, Polymer Electrolytes, Annual Review of Materials Research 43(1) (2013) 503-525.

[14] R.C. Agrawal, G.P. Pandey, Solid polymer electrolytes: materials designing and allsolid-state battery applications: an overview, Journal of Physics D: Applied Physics 41(22) (2008) 223001.

[15] D. Golodnitsky, E. Strauss, E. Peled, S. Greenbaum, Review-On Order and Disorder in Polymer Electrolytes, Journal of The Electrochemical Society 162(14) (2015) A2551-A2566.

[16] Q. Yang, Z. Zhang, X.-G. Sun, Y.-S. Hu, H. Xing, S. Dai, Ionic liquids and derived materials for lithium and sodium batteries, Chemical Society Reviews 47(6) (2018) 20202064. 
[17] G.A. Giffin, Ionic liquid-based electrolytes for "beyond lithium" battery technologies, Journal of Materials Chemistry A 4(35) (2016) 13378-13389.

[18] E. Quartarone, P. Mustarelli, A. Magistris, PEO-based composite polymer electrolytes, Solid State Ionics 110(1) (1998) 1-14.

[19] M.A.K.L. Dissanayake, L.R.A.K. Bandara, R.S.P. Bokalawala, P.A.R.D. Jayathilaka, O.A. Ileperuma, S. Somasundaram, A novel gel polymer electrolyte based on polyacrylonitrile (PAN) and its application in a solar cell, Materials Research Bulletin 37(5) (2002) 867-874.

[20] J. Vondrák, M. Sedlaríková, J. Reiter, D. Kašpar, PMMA Based Gel Polymer Electrolytes, in: C. Julien, Z. Stoynov (Eds.), Materials for Lithium-Ion Batteries, Springer Netherlands, Dordrecht, 2000, pp. 623-625.

[21] P. Martins, A.C. Lopes, S. Lanceros-Mendez, Electroactive phases of poly(vinylidene fluoride): Determination, processing and applications, Progress in Polymer Science 39(4) (2014) 683-706.

[22] J. Barbosa, J. Dias, S. Lanceros-Méndez, C. Costa, Recent Advances in Poly(vinylidene fluoride) and Its Copolymers for Lithium-Ion Battery Separators, Membranes 8(3) (2018) 45.

[23] I.-H. Kim, D.H. Baik, Y.G. Jeong, Structures, electrical, and dielectric properties of PVDF-based nanocomposite films reinforced with neat multi-walled carbon nanotube, Macromolecular Research 20(9) (2012) 920-927.

[24] J. Guan, C. Xing, Y. Wang, Y. Li, J. Li, Poly (vinylidene fluoride) dielectric composites with both ionic nanoclusters and well dispersed graphene oxide, Composites Science and Technology 138 (2017) 98-105.

[25] W.X. Ruan, J.B. Liao, G.Q. Wang, X.W. Zhang, J. Wang, J.B. Ji, Hydrophilic modification of polyvinylidene fluoride (PVDF) membrane with ionic liquid grafted Nano-SiO2 particles, 2015.

[26] E. Thomas, C. Parvathy, N. Balachandran, S. Bhuvaneswari, K.P. Vijayalakshmi, B.K. George, PVDF-ionic liquid modified clay nanocomposites: Phase changes and shish-kebab structure, Polymer 115 (2017) 70-76.

[27] C. Xing, M. Zhao, L. Zhao, J. You, X. Cao, Y. Li, Ionic liquid modified poly(vinylidene fluoride): crystalline structures, miscibility, and physical properties, Polymer Chemistry 4(24) (2013) 5726-5734. 
[28] C. Xing, J. You, Y. Li, J. Li, Nanostructured Poly(vinylidene fluoride)/Ionic Liquid Composites: Formation of Organic Conductive Nanodomains in Polymer Matrix, The Journal of Physical Chemistry C 119(36) (2015) 21155-21164.

[29] A. Chinnappan, H. Kim, I.T. Hwang, An efficient and recyclable PVDF-IL nanofiber composite for the reduction of functionalized carbonyl compounds, Chemical Engineering Journal 191 (2012) 451-456.

[30] Shalu, S.K. Chaurasia, R.K. Singh, S. Chandra, Thermal Stability, Complexing Behavior, and Ionic Transport of Polymeric Gel Membranes Based on Polymer PVdFHFP and Ionic Liquid, [BMIM][BF4], The Journal of Physical Chemistry B 117(3) (2013) 897-906.

[31] H.Z. Chen, P. Li, T.-S. Chung, PVDF/ionic liquid polymer blends with superior separation performance for removing $\mathrm{CO} 2$ from hydrogen and flue gas, International Journal of Hydrogen Energy 37(16) (2012) 11796-11804.

[32] D.M. Correia, R. Sabater i Serra, J.A. Gómez Tejedor, V. de Zea Bermudez, A. Andrio Balado, J.M. Meseguer-Dueñas, J.L. Gomez Ribelles, S. Lanceros-Méndez, C.M. Costa, Ionic and conformational mobility in poly(vinylidene fluoride)/ionic liquid blends: Dielectric and electrical conductivity behavior, Polymer 143 (2018) 164-172.

[33] D. Okada, H. Kaneko, K. Kato, S. Furumi, M. Takeguchi, Y. Yamamoto, Colloidal Crystallization and Ionic Liquid Induced Partial $\beta$-Phase Transformation of Poly(vinylidene fluoride) Nanoparticles, Macromolecules 48(8) (2015) 2570-2575.

[34] J.R. Sangoro, A. Serghei, S. Naumov, P. Galvosas, J. Kärger, C. Wespe, F. Bordusa, F. Kremer, Charge transport and mass transport in imidazolium-based ionic liquids, Physical Review E 77(5) (2008) 051202.

[35] J.R. Sangoro, C. Iacob, A. Serghei, C. Friedrich, F. Kremer, Universal scaling of charge transport in glass-forming ionic liquids, Physical Chemistry Chemical Physics 11(6) (2009) 913-916.

[36] J.R. Sangoro, C. Iacob, W.K. Kipnusu, M. Jasiurkowska, R. Valiullin, C. Friedrich, J. Kärger, F. Kremer, Rotational and translational diffusion in glass-forming N,N,diethyl-3-methylbenzamide (DEET), Soft Matter 7(22) (2011) 10565-10568.

[37] C. Krause, J.R. Sangoro, C. Iacob, F. Kremer, Charge Transport and Dipolar Relaxations in Imidazolium-Based Ionic Liquids, The Journal of Physical Chemistry B 114(1) (2010) 382-386. 
[38] B.-E. El Mohajir, N. Heymans, Changes in structural and mechanical behaviour of PVDF with processing and thermomechanical treatments. 1. Change in structure, Polymer 42(13) (2001) 5661-5667.

[39] C. Ribeiro, C.M. Costa, D.M. Correia, J. Nunes-Pereira, J. Oliveira, P. Martins, R. Gonçalves, V.F. Cardoso, S. Lanceros-Méndez, Electroactive poly(vinylidene fluoride)based structures for advanced applications, Nature Protocols 13 (2018) 681.

[40] R. Hagiwara, J.S. Lee, Ionic Liquids for Electrochemical Devices, Electrochemistry 75(1) (2007) 23-34.

[41] I.A. Shkrob, T.W. Marin, Y. Zhu, D.P. Abraham, Why Bis(fluorosulfonyl)imide Is a "Magic Anion" for Electrochemistry, The Journal of Physical Chemistry C 118(34) (2014) 19661-19671.

[42] K. Nakamura, T. Saiwaki, K. Fukao, Dielectric Relaxation Behavior of Polymerized Ionic Liquid, Macromolecules 43(14) (2010) 6092-6098.

[43] J.R. Sangoro, F. Kremer, Charge Transport and Glassy Dynamics in Ionic Liquids, Accounts of Chemical Research 45(4) (2012) 525-532.

[44] W.-L. Yuan, X. Yang, L. He, Y. Xue, S. Qin, G.-H. Tao, Viscosity, Conductivity, and Electrochemical Property of Dicyanamide Ionic Liquids, Frontiers in Chemistry 6(59) (2018).

[45] A.C. Lopes, C.M. Costa, R.S.i. Serra, I.C. Neves, J.L.G. Ribelles, S. LancerosMéndez, Dielectric relaxation, ac conductivity and electric modulus in poly(vinylidene fluoride)/NaY zeolite composites, Solid State Ionics 235 (2013) 42-50.

[46] P. Sippel, P. Lunkenheimer, S. Krohns, E. Thoms, A. Loidl, Importance of liquid fragility for energy applications of ionic liquids, Scientific Reports 5 (2015) 13922.

[47] P. Wang, P. Xu, H. Wei, H. Fang, Y. Ding, Effect of block copolymer containing ionic liquid moiety on interfacial polarization in PLA/PCL blends, Journal of Applied Polymer Science 135(16) (2018) 46161.

[48] A. Serghei, M. Tress, J.R. Sangoro, F. Kremer, Electrode polarization and charge transport at solid interfaces, Physical Review B 80(18) (2009) 184301.

[49] F. Frenzel, R. Guterman, A.M. Anton, J. Yuan, F. Kremer, Molecular Dynamics and Charge Transport in Highly Conductive Polymeric Ionic Liquids, Macromolecules 50(10) (2017) 4022-4029.

[50] Z. Zheng, X. Xia, X. Zeng, X. Li, Y. Wu, J. Liu, L. Zhang, Theoretical Model of Time-Temperature Superposition Principle of the Self-Healing Kinetics of 
Supramolecular Polymer Nanocomposites, Macromolecular rapid communications (2018) e1800382-e1800382.

[51] H. Namikawa, Characterization of the diffusion process in oxide glasses based on the correlation between electric conduction and dielectric relaxation, Journal of NonCrystalline Solids 18(2) (1975) 173-195.

[52] J.C. Dyre, The random free-energy barrier model for ac conduction in disordered solids, Journal of Applied Physics 64(5) (1988) 2456-2468.

[53] E. Thoms, P. Sippel, D. Reuter, M. Weiß, A. Loidl, S. Krohns, Dielectric study on mixtures of ionic liquids, Scientific Reports 7(1) (2017) 7463.

[54] M.T. Viciosa, G. Santos, A. Costa, F. Danède, L.C. Branco, N. Jordão, N.T. Correia, M. Dionísio, Dipolar motions and ionic conduction in an ibuprofen derived ionic liquid, Physical Chemistry Chemical Physics 17(37) (2015) 24108-24120. 